\title{
AHP-Based Evaluation Model for Optimal Selection Process of Patching Materials for Concrete Repair: Focused on Quantitative Requirements
}

\author{
Jeong-Yun Do ${ }^{1)}$, and Doo-Kie Kim ${ }^{2}$,* \\ (Received March 14, 2012, Revised April 26, 2012, Accepted May 21, 2012, Published online July 1, 2012)
}

\begin{abstract}
The process of selecting a repair material is a typical one of multi-criteria decision-making (MCDM) problems. In this study Analytical Hierarch Process was applied to solve this MCDM problem. Many factors affecting a process to select an optimal repair material can be classified into quantitative and qualitative requirements and this study handled only quantitative items. Quantitative requirements in the optimal selection model for repair material were divided into two parts, namely, the required chemical performance and the required physical performance. The former is composed of alkali-resistance, chloride permeability and electrical resistivity. The latter is composed of compressive strength, tensile strength, adhesive strength, drying shrinkage, elasticity and thermal expansion. The result of the study shows that this method is the useful and rational engineering approach in the problem concerning the selection of one out of many candidate repair materials even if this study was limited to repair material only for chloride-deteriorated concrete.
\end{abstract}

Keywords: concrete repair, repair materials, AHP, MCDM, optimal selection.

$\begin{array}{ll}\text { Abbreviations } \\ \text { MCDM } & \text { Multi criteria decision making } \\ \text { PC } & \text { Performance criteria } \\ \text { MRPC } & \text { Minimal required performance criteria } \\ \text { PEI } & \text { Performance evaluation item } \\ \text { PI } & \text { Performance index }\end{array}$

\section{Introduction}

Recently, many repair materials which have long been used in concrete repair work have their own characteristics, applications, advantages, and limitations. When selecting materials for engineering designs, we must have a clear understanding of the functional requirements for each individual component. In selecting materials for an application, technological considerations of material characteristics are important. The economic aspects of materials and cost of

\footnotetext{
${ }^{1)}$ Research Institute for Environment and Construction, Kunsan National University, Kunsan City, Jeonbuk 573-701, Korea.

${ }^{2)}$ Civil Engineering, College of Engineering, Kunsan National University, Kunsan City, Jeonbuk 573-701, Korea.

*Corresponding Author; E-mail: kim2kie@chol.com Copyright ( $\odot$ The Author(s) 2012. This article is published with open access at Springerlink.com
}

manufacturing are equally important. Basically, the more service life of concrete repaired with some material can obtain some accompanying benefit like cost and resource savings etc. (Beushausen and Alexander 2007; Chawalwala 1999; Chen 1994; Mailvaganam 2001).

Long service life of concrete repairs, to a large degree, depends on correct choice and use of repair materials. In recent a large number of different proprietary brands of repair materials have been introduced. They include cementitious, polymer-based and polymer-modified cementitious materials. As explained in Fig. 1, the precise formulation of the materials varies from one supplier to another, and even properties may vary significantly within one family group. Generally, repair materials similar to the concrete substrate or easily available repair materials or the material with which the user is familiar have been applied to the repair work with being wrongly regarded to be the optimal materials. Additionally, just a few materials are misunderstood into being better materials among various concrete repair materials available. This can cause a problem in the repair work in terms of the qualitative performance as well as the quantitative performance (Cusson and Mailvaganam 1996; Do 2009; Emmons et al. 2000; Emmons 1995; ICRINo.320.2R 2009; Keoleian et al. 2005; Kosednar and Mailvaganam 2005; Nabhan 2007; Singh 2005; Vaysburd et al. 2000; Vaysburd 2000).

Namely when selecting materials for repair design, a clear understanding of the functional requirements for each repair application is required and various important criteria or attributes need to be considered. Repair material selection 


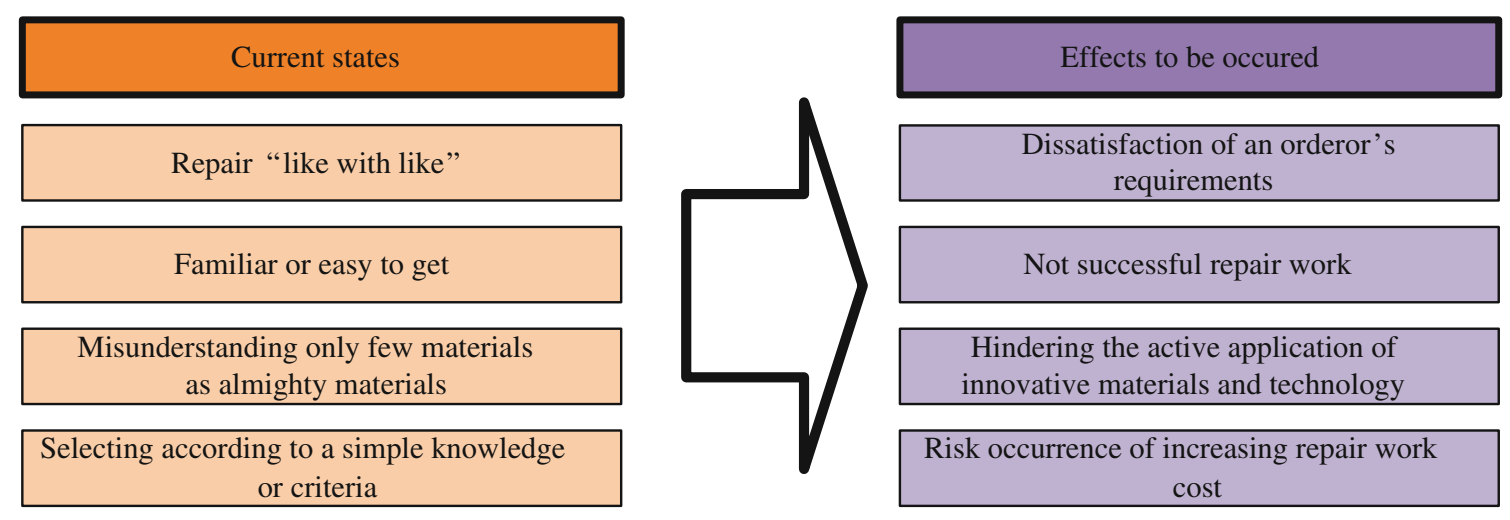

Fig. 1 Current state of repair work and its anticipated effect.

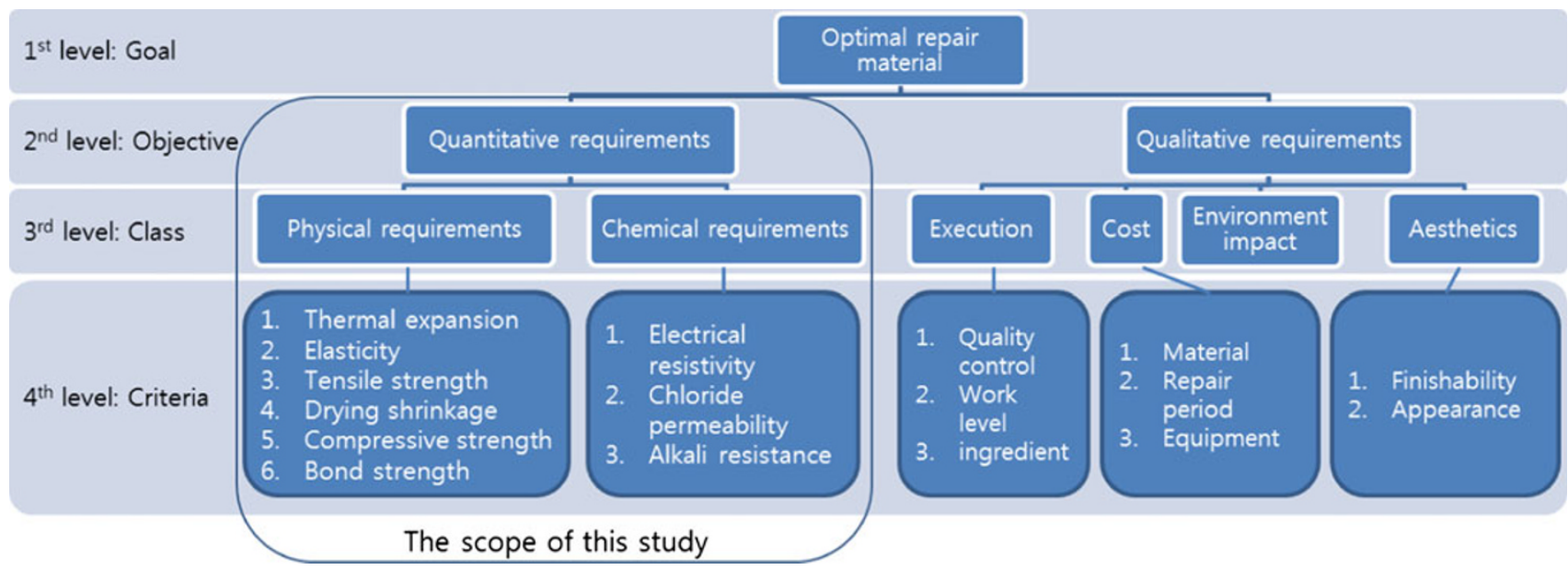

Fig. 2 The scope of this study and hierarchy structure of performance criteria affecting repair materials selection problem.

attribute is defined as an attribute that influences the selection of a repair material for a given application. These criteria include: physical properties, electrical properties, mechanical properties, chemical properties, manufacturing properties, material cost, material impact on environment, aesthetics, recycling, etc. (Do 2009; Vaysburd et al. 2000; Vaysburd et al. 2000; ACI546.3R-06 2006; ACI546R-04 2004; Al-Zahrani et al. 2003; Rizzo and Sobelman 1989).

The selection of an optimal material for repair application from among two or more alternative materials on the basis of two or more criteria is a multiple criteria decision making (MCDM) problem. Various approaches to this problem had been proposed in the past to help address the issue of material selection and the detailed explanations about this are in the following chapter 2. Liao (1996) presented a fuzzy multi-criteria decision making method for material selection. However, the method is complicated and requires much more computation. Ashby (2000, 2005; Ashby and Johnson 2002) proposed multi-objective optimization in materials design and selection using 'utility' functions. Even though the method is simple but it is not efficient only to be useful for initial screening of materials. There is some literature applying AHP method to solve each research issue. Smith et al. (1995, 1997; Smith and Hashemi 2006) used AHP method to characterize the bridge material decision process of highway officials in selected states and developed a behavioral model of bridge material selection for several states and for several levels of decision makers. Chen (1994) proposed AHP approach, a decision-making method based on pairwise comparisons between criteria, to construct an evaluation structure with criteria and associated weights of convention site selection. Anyway, there is no standard technique used by the designer to select a right material for an application. As stated previous paragraphs, a material is sometimes selected based on what worked before in similar conditions or what a competitor is using in their product. In the current competitive market, this short-cut method may cause one to overlook new emerging technologies and may put the product in a less competitive position. The job of material and design engineers is to consider all possible opportunities to utilize new material systems and technologies for the reduction of manufacturing cost and weight for the same or increased performance (Beushausen and Alexander 2007; Do 2009; Emmons et al. 2000; Emmons 1995; Kosednar and Mailvaganam 2005; Singh 2005; Vaysburd et al. 2000a; b; Rizzo and Sobelman 1989; Smith et al. 1997; Saaty and Vargas 1987).

Even though a good amount of research work had been carried out in the past on materials selection, there is a need for a simple, systematic and logical scientific method or mathematical tool to guide designers in taking a proper material selection decision. The objective of a material selection procedure is to identify the material selection factors and obtain the most appropriate combination of material 
selection factors in conjunction with the real requirement. As shown in Fig. 2 the decision-making factors for selecting an appropriate repair material can be can be mainly classified into the quantitative and the qualitative. In this study the only quantitative requirements were considered as main determinant of selecting repair materials for repairing the chloride-deteriorated concrete. Although various techniques exist for modeling decision making, the analytical hierarchy process was chosen for this study. This study presents the decision-making support process by means of AHP method to be applied to select optimal patching repair materials for chloride-deteriorated concrete member.

\section{MCDM and AHP}

\subsection{MCDM and Material Selection}

When choosing a new material or replacing an existing one in concrete repair work, experts usually apply trial and error methods or judge just based on previous experimentation. It must be noted that in choosing the right material, there is not always a single definite criterion of selection and the designers and engineers have to take into account a large number of material selection criteria. These material selection criteria range from mechanical to electrical properties and corrosion resistance. With regards to each material selection criterion, a wide range of material properties and performance attributes exist and decision making in the presence of multiple, generally conflicting criteria is known as multiple criteria decision making (MCDM) (Chawalwala 1999; Al-Zahrani et al. 2003; Ashby 2000, 2005; Bamkin and Piearcey 1990; Sapuan 2001; Fitch and Cooper 2004; Steeves and Fleck 2004; Ishii 1996).

\subsection{MCDM Methods}

\subsubsection{Non-Compensatory Methods}

Non-compensatory methods do not permit tradeoffs between attributes. An unfavorable value in one attribute cannot be offset by a favorable value in other attributes. Each attribute must stand on its own. Hence comparisons are made on an attribute-by-attribute basis. The MCDM methods in this category are credited for their simplicity. Examples of these methods include: (Chawalwala 1999; Chen et al. 1994; Liao 1996; Ashby 2005; Saaty and Vargas 1987; Bamkin and Piearcey 1990; Fitch and Cooper 2004; Steeves and Fleck 2004; Ishii 1996; Rao 2008; Rao and Davim 2008; Jalham 2006; McDonald et al. 2000; Saaty 1994; Saaty 1994; Shanian and Savadogo 2006; Rao 2006; Jee and Kang 2000; Sirisalee et al. 2004; Saaty 1990; Zhou et al. 2009; Vokurka et al. 1996).

2.2.1.1 Dominance Method Eliminate all dominated alternatives. There could be more than one solutions generated by this method.

2.2.1.2 Maxmin Method Find the weakest attribute value (min) of each alternative and then choose the alternative with the best $(\max )$ weakest attribute value. The logic is that a chain is as strong as its weakest link. This method is applicable only when attribute values are comparable with one another, either measured in the same unit or transformed to a common scale.

2.2.1.3 Maxmax Method In contrast to the Maxmin method, the Maxmax method selects an alternative by its best attribute value. It is also applicable only when attributes are comparable.

2.2.1.4 Conjunctive Constraint Method By setting up a minimum standard for each attribute, the alternative selection or evaluation process is simplified to compare each attribute against its standard. If the standard reflects the decision maker's expectations, the obtained solutions are satisfying solutions.

2.2.1.5 Disjunctive Constraint Method This method evaluates an alternative on its best attribute regardless of all other attributes. These techniques may have their application domains in which they are reasonable, but they may not be very useful for general decision making.

\subsubsection{Compensatory Methods}

Compensatory methods permit tradeoffs between attributes. A slight decline in one attribute is acceptable if it is compensated by some enhancement in one or more other attributes. Compensatory methods can be classified into the following four subgroups (Chawalwala 1999; Chen et al. 1994; Al-Zahrani et al. 2003; Liao 1996; Ashby 2000, 2005; Smith and Hashemi 2006; Saaty and Vargas 1987; Bamkin and Piearcey 1990; Sapuan 2001; Fitch and Cooper 2004; Steeves and Fleck 2004; Ishii 1996; Jalham 2006; McDonald et al. 2000; Saaty 1994a, b; Shanian and Savadogo 2006; Jee and Kang 2000; Sirisalee et al. 2004; Saaty 1990; Zhou et al. 2009; Vokurka et al. 1996; Stuart and Sommerville 1998; Holloway 1998).

2.2.2.1 Scoring Methods The scoring method selects or evaluates an alternative according to its score (or utility). Utility or score is used to express the decision maker's preference. It transforms attribute values into a common preference scale such as $[0,1]$ so that comparisons between different attributes becomes possible. A very popular method in this category is the Simple Additive Weighting method. This method calculates the overall score of an alternative as the weighted sum of the attribute scores or utilities. The Analytical Hierarchy Process (AHP) is another popular method in this category. This method calculates the scores for each alternative based on pairwise comparisons.

2.2.2.2 Compromising Methods The compromising method selects an alternative that is closest to the ideal solution. The Technique for Order Preference by Similarity to Ideal Solution (TOPSIS) method belongs to this category. This method first normalizes the decision matrix of a 
MCDM problem. Then based on the normalized decision matrix, it calculates the weighted distances of each alternative from an ideal solution and a nadir solution. A solution relatively close to the ideal solution and far from the nadir solution is evaluated to be the best.

2.2.2.3 Concordance Methods The concordance method generates a preference ranking which best satisfies a given concordance measure. The Linear Assignment Method is one of the examples in this family. In this method it is believed that an alternative having many highly ranked attributes should be ranked high.

\subsection{Overview of AHP}

As stated in previous section, although various techniques exist for modeling decision making problem (MCDM), the AHP was chosen for this study. The AHP have the strength capable of being used as a qualitative, as well as a quantitative model of decision making. The Analytic Hierarchy Process, developed by Thomas Saaty in the early 1970s, allowed us to quantify and aggregate subjective opinions. Saaty states that, the practice of decision making is concerned with weighing the alternatives which fulfill a set of desired objectives. This multi-criterion structures the decision process into a hierarchy. Through a set of pairwise comparisons at each level of the hierarchy, a matrix can be developed, where the entities indicate the strength with which one element dominates another with respect to a given criterion (Saaty and Vargas 1987; Yurdakul 2004; Zahedi 1986; Vaidya and Kumar 2006; Zahedi 1986; Saaty 1980).

\subsubsection{Descriptions of AHP}

Three principles used in the AHP for problem solving are as follows: (1) decomposition-structuring the elements of the problem into a hierarchy, (2) comparative judgmentsgenerating a matrix of pairwise comparisons of all elements in a level with respect to each related element in the level immediate above it where the principal right eigenvector of the matrix provides ratio-scaled priority ratings for the set of elements compared, and (3) synthesis of priorities - calculating the global priority of the elements at the lowest level of the hierarchy (i.e., the alternatives).

Decomposition: Decomposition into a hierarchy is based on previous studies and empirical experiences. AHP demands that, the problem be structured by the participants in the decision-making process, although it is not essential that all participants in the planning process agree on every component of the problem. In addition, it is important that all essential elements relevant to the problem are covered within the hierarchy structure. In its most typical form, a hierarchy is very often structured from the top (objectives from the managerial standpoint) through the immediate level (criteria and sub criteria that subsequent levels depend on), and on to the lowest level (which is usually a list of alternatives)

Comparative judgments by pairwise comparison: Once a hierarchy has been developed, one moves to data collection, thus having the pair-wise comparisons needed to determine the relative importance of the elements in each level. The decision makers begin the prioritization procedure to determine the relative importance of the elements in each level. The criteria and sub-criteria are not equally important to the decision at each level of the hierarchy, and each alternative rate differently on each criterion. AHP can provide an analytical process that is able to combine and consolidate the evaluations of the alternatives and criteria by either an individual or group involved in the decision-making task.

The comparison of two elements, that is pairwise comparison in AHP, greatly reduces the conceptual complexity of an analysis. This simplification involves assumptions that considered as reasonable by Satty and others (Saaty and Vargas 1987; Saaty 1994a, b, 1990, 2008). Given a pairwise comparison, the analysis involves three tasks: (1) developing a comparison matrix at each level of the hierarchy starting from the second level and working down, (2) computing the relative weights for each element of the hierarchy, and (3) estimating the consistency ratio to check the consistency of the judgment. Elements in each level are compared in pairs with respect to their importance to an element in the next higher level. Starting at the top of the hierarchy and working down, the pair-wise comparisons at a given level can be reduced to a number of square matrices $\mathrm{A}=\left[a_{i j}\right]_{n \times n}$ as in the following equation:

$$
\left(\begin{array}{cccc}
a_{11} & a_{12} & \cdots & a_{1 n} \\
a_{21} & a_{22} & \cdots & a_{2 n} \\
\vdots & \vdots & \ddots & \vdots \\
a_{n 1} & a_{n 2} & \cdots & a_{n n}
\end{array}\right)=\left(\begin{array}{cccc}
a_{11} & a_{12} & \cdots & a_{1 n} \\
1 / a_{12} & a_{22} & \cdots & a_{1 n} \\
\vdots & \vdots & \ddots & \vdots \\
1 / a_{1 n} & 1 / a_{2 n} & \cdots & a_{n n}
\end{array}\right)
$$

The matrix has reciprocal properties, which are

$$
a_{j i}=\frac{1}{a_{i j}}
$$

In AHP, a scale of relative importance from 1 to 9 for making subjective pair-wise comparisons is recommended (see Table 1). After all pair-wise comparison matrices are formed, the vector of weights, $\omega=\left[\omega_{1}, \omega_{2}, \ldots, \omega_{n}\right]$, is computed on the basis of Satty's eigenvector procedure(Saaty 1994a, b, 1990, 2008). The computation of the weights involves two steps. First, the pairwise comparison matrix, $\mathrm{A}=\left[a_{i j}\right]_{n \times n}$, is normalized by Eq. (3), and then the weights are computed by Eq. (4).

Normalization

$$
a_{i j}^{*}=\frac{a_{i j}}{\sum_{i=1}^{n} a_{i j}}
$$

For all $j=1,2, \ldots, n$.

Weight calculation is made as follows;

$$
\omega_{i j}=\frac{\sum_{j=1}^{n} a_{i j}^{*}}{n}
$$

For all $i=1,2, \ldots, n$. 
Table 1 9-point intensity of relative importance scale.

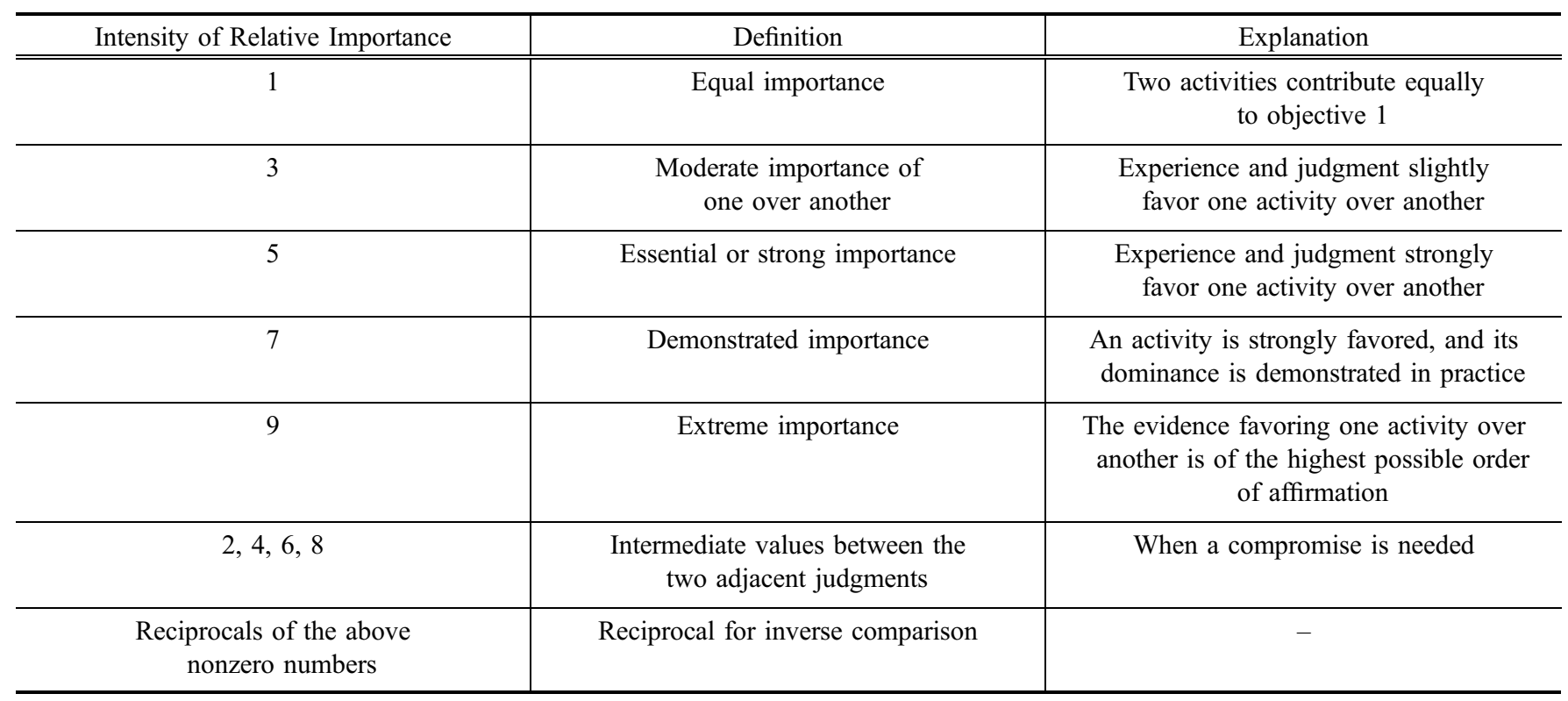

Table 2 Random inconsistency indices (RI) for $n=10$.

\begin{tabular}{c|c|c|c|c|c|c|c|c|c|c|c}
\hline $\mathrm{N}$ & 1 & 2 & 3 & 4 & 5 & 6 & 7 & 8 & 9 & 10 \\
\hline \hline $\mathrm{RI}$ & 0.00 & 0.00 & 0.58 & 0.9 & 1.12 & 1.24 & 1.32 & 1.41 & 1.46 & 1.49 \\
\hline
\end{tabular}

As shown in Eq. (5) a relationship between the vector weights, $\omega$, and the pairwise comparison matrix A exits.

$\mathrm{A} \cdot \omega=\lambda_{\max } \cdot \omega$

The $\lambda_{\max }$ value is an important validating parameter in AHP and is used as a reference index to screen information by calculating the consistency ratio $(C R)$ of the estimated vector. To calculate the $C R$, the consistency index $(C I)$ for each matrix of order $n$ can be obtained from Eq. (6).

$$
C I=\frac{\lambda_{\max }-n}{n-1}
$$

Then, CR can be calculated using Eq. (5):

$$
C R=\frac{C I}{R I}
$$

where, RI is the random consistency index obtained from a randomly generated pair-wise comparison matrix. Table 2 shows the value of the $R I$ from matrices of order 1 to 10 . If $C R<0.1$, then the comparisons are acceptable. If, however, $C R \geq 0.1$, then the values of the ratio are indicative of inconsistent judgments. In such cases, the original values in the pairwise comparison matrix A should be reconsidered and revised. To obtain an aggregate measure of the pairwise comparisons of all individuals involved in a decision problem, the geometric mean of the individual assessments using Eq. (8) is used.

$$
a_{i j}^{h p}=\sqrt[Q]{\prod_{q=1}^{Q} a_{i j}^{q}}
$$

Where, $a_{i j}^{q}$ is an element of matrix A of an individual $q(q=1,2, \ldots, Q)$, and is the geometric mean of all individuals $a_{i j}^{h p}$. The group CR is calculated according to Eqs. (6) and (7).

Synthesis of priorities: The local priorities that express the relative impact of the set of elements on an element in the level immediately can be generated by using the set of pairwise comparison matrices. A set of eigenvectors for each matrix are computed by Eq. (5) and normalized to unify the result so as to obtain the vectors of priorities. The geometric mean is used to aggregate the pairwise comparisons for all samples. The local weights of the factors and attributes, and the consistency ratio of each matrix, are analyzed by the procedure aforementioned. Global weights are synthesized form the level down by multiplying the local weights by the corresponding criterion in the level above and adding them for each element in a level according to the criteria it affects (Saaty and Vargas 1987; Saaty 1994, b, 1990, 2008).

\section{Optimal Repair Selection Procedure}

There is no standard technique used by the designer to select a right material for a given application. Sometimes, a material is selected based on what worked before in similar conditions or what a competitor is using in their products as mentioned in the introduction of this paper. In the current competitive construction maintenance market, this obsolete short-cut method may cause one to overlook new emerging technologies and may put the repair product in a less competitive position. The job of materials and design engineers is to consider all possible opportunities to utilize new 
material systems and technologies for the reduction of the same or increased performance.

A large number of repair materials and the many manufacturing processes available to the engineer, coupled with the complex relationships between the different selection parameter, often make the selection of a materials for a given application environment a difficult task. If the selection process is carried out randomly, there will be the risk of overlooking a possible attractive alternative material. The risk can be reduced by adopting a systematic material selection procedure. This section presents the quantitative material selection method $\mathrm{s}$ for the evaluation of a suitable repair material in a given application.

\subsection{Entire Process for Optimal Material Selection Model}

A systematic approach to the material selection problem for repairing the deteriorated concrete member or structure by applying the concept of AHP is proposed in Fig. 3. Each repair material in the candidate group is an alternative to be selected for the application to concrete repair work. The system assesses the suitability of all materials in the candidates, eliminates unsuitable materials from further consideration, give a final ranking to all of the suitable materials.

More specifically, the approximate solving process of AHP based repair material selection problem as shown in Fig. 3 is composed of Pre-Evaluation phase in which the requirements is determined to be an evaluation criterion, Evaluation phase in which possible materials are selected by screening various commercial repair materials and the performances of each possible material are evaluated to narrow the fields of possible materials to a few optimum candidates, and finally Post-evaluation and review phase in which one or two, at most three of the optimum candidate repair materials are tested and evaluated to verify these performances. Details of the important concepts of the methodology are explained in following sections.

\subsection{Pre-Evaluation Phase \\ 3.2.1 Setting Minimal Requirements and Deter- mining the Requirements}

There are many factors affecting the selection of repair materials as shown in Fig. 2, which result in considering the selection process of a repair material into the complex problem of multi-criteria decision-making problem. Before preparing selection model, the required performance criteria (PC) are decided. PC means chemical and physical minimum performances that repair material candidates must minimally retain. But it is very difficult and controversial problem because the minimal requirements are composed of numerous performance and any code/standards also have not suggested the certain value. In spite of these problems the setting up of minimal requirements is basically necessary to filter a lot of commercial repair materials and to further narrow the field of possible materials to a few optimum candidates by reducing the number of repair material candidate for easy evaluation.
The minimal performance requirement of repair materials was decided as listed in Table 3 based on the study of various literatures, especially, Emmons, ACI code and EN 1504 etc. in order to ensure the satisfactory and reliable repair effects (ICRINo.320.2R 2009; ACI546.3R-06 2006; ACI546R-042004; ACI201.2R 2004; ACI548.1R 2004; EN 1504; ICRINo.320.1R 1996; ICRINo.330.1 2006; Raupach 2006; Standard 2004). The repair material family appropriate in the given application environment is too many. Thus in this study six repair materials in the material family were chosen to narrow the field of repair material selection. These chosen repair materials satisfy the minimal performance requirements in listed in Table 3.

Table 3 also lists the measurement methods of each performance evaluation item (PEI). These various performance requirements for materials for repair are classified the quantitative performances into the chemical and the physical performance except qualitative performances because the concern of this study focuses on the consideration of the only quantitative performance among the numerous performances as shown in Fig. 2. Subsequently after selecting the candidate repair materials meeting minimal requirements, the physical and chemical performance of these possible materials to a few optimum candidates will be investigated through measurements method listed in Table 3 .

\subsubsection{Indexing the Physical and Chemical Performances of Repair Materials}

Indexing the performance values is necessary to apply the physical and chemical performances of each repair material listed in Table 4 to the selection process.

Absolute evaluation method was used in order to index the physical and chemical performances of each repair material listed in Table 4. This absolute evaluation method is one of two basic methods of valuing an object. The most frequently used method is relative evaluation, which compares an object's valuation with those of other object. The absolute evaluation method uses absolute, or intrinsic, valuation. Namely this method assesses the objects under different criteria and standards. No comparison is made between objects. Detailed explanations are made in references (Sapuan 2001; Saaty 1994, 1980, 1990; Shanian and Savadogo 2006; Sirisalee et al. 2004; Vaidya and Kumar 2006; Zahedi 1986; Vargas 1990).

After the performances of repair materials are expressed as a form of indicator such as very low, low, moderate and negligible, the indicators are assigned suitable numbers in this absolute evaluation method. Performance index was prepared using a method of pairwise comparison defined in AHP as being explained in Tables 5 and 6. Performance indices calculated this pairwise comparison correspond to the verbal indicators 'very low, low, moderate and negligible'. In Tables 5 and 6 the consistency ratio is 0.001 and 0.004 which is much less than the allowed value of 0.1 . Thus, there is good consistency in the judgments made. 


\begin{tabular}{|c|c|c|}
\hline Stages of Design & \multicolumn{2}{|l|}{ Stages of Materials Selection } \\
\hline \multicolumn{3}{|c|}{ 1. Required Performance criteria Configuration } \\
\hline \multirow{3}{*}{$\begin{array}{l}\text { Initial screening: } \\
\text { Conceptual } \\
\text { design step }\end{array}$} & $\begin{array}{l}\text { - } \quad \text { Performance Evaluation Item(PEI) based on the } \\
\text { requirements of an application } \\
\text { - } \quad \text { Performance Evaluation method } \\
\text { - } \quad \text { To narimal Required Performance Criteria(MRPC) } \\
\text { possible repair materials proper to given application }\end{array}$ & $\begin{array}{l}\text { Pre- } \\
\text { Evaluation } \\
\text { phase }\end{array}$ \\
\hline & 2. Performance Measurement & \multirow{4}{*}{$\begin{array}{l}\text { Evaluation } \\
\text { phase }\end{array}$} \\
\hline & $\begin{array}{l}\text { - Choosing repair material family proper to a given } \\
\text { application } \\
\text { - Screening material family by applying MRPC } \\
\text { - Selection of possible repair materials } \\
\text { Measuring the performance of the screened possible } \\
\text { repair materials(repair material candidates) }\end{array}$ & \\
\hline \multicolumn{2}{|r|}{ 3. Modeling Material Selection } & \\
\hline \multirow[t]{2}{*}{$\begin{array}{l}\text { Comparing } \\
\text { alternative } \\
\text { solutions: } \\
\text { Embodiment } \\
\text { design step }\end{array}$} & $\begin{array}{l}\text { - Hierarchy-structure of each performance evaluation } \\
\text { item(PEI) } \\
\text { - } \quad \text { Performance Indies(PI) Calculation of each PEI } \\
\text { - } \quad \text { Local relative weight of PEI at each level } \\
\text { weights of upper levels(Weighted } \mathrm{PEI} \text { ) } \\
\text { - Weighted performance indices of each repair material } \\
\text { candidate weighted PEI }\end{array}$ & \\
\hline & \multicolumn{2}{|l|}{ 4. Ranking candidate materials and Final Selection } \\
\hline $\begin{array}{l}\text { Selection of } \\
\text { optimum } \\
\text { solution: } \\
\text { Parametric } \\
\text { design step }\end{array}$ & $\begin{array}{l}\text { - Final evaluation value calculation reflecting global } \\
\text { relative weight of each PEI at lowest level } \\
\text { - Ordering the viable candidates by the value of weighted } \\
\text { performance indices of each material candidate } \\
\text { Seeking supporting information for the top-ranked } \\
\text { candidates } \\
\text { - Exploring aspects of their past history, established } \\
\text { uses, their behavior in relevant environments, their } \\
\text { availability etc. } \\
\text { - Determination the candidates having a sufficient reliable } \\
\text { information as optimal repair material alternative }\end{array}$ & $\begin{array}{l}\text { Post- } \\
\text { Evaluation } \\
\text { and } \\
\text { Review } \\
\text { phase }\end{array}$ \\
\hline
\end{tabular}

Fig. 3 Stages of design and the related stages of materials selection.

Table 3 Minimal performance requirements and those measurements.

\begin{tabular}{|c|c|c|c|c|}
\hline Performance & Sub-performance & $\begin{array}{c}\text { Performance evaluation } \\
\text { item }\end{array}$ & $\begin{array}{c}\text { Minimal performance } \\
\text { criteria }\end{array}$ & Measurements \\
\hline \multirow{9}{*}{$\begin{array}{c}\text { Quantitative evaluation } \\
\text { performance }\end{array}$} & \multirow[t]{3}{*}{ Chemical performance } & Electrical resistivity & More than $12 \mathrm{k} \Omega \mathrm{cm}$ & Resitest- 4000 \\
\hline & & Chloride permeability & Less than $4000 \mathrm{C}$ & ASTM C1202 \\
\hline & & Alkali-resistance & Less than $3 \%$ & KS F 4042 \\
\hline & \multirow[t]{6}{*}{ Physical performance } & Compressive strength & More than $27 \mathrm{MPa}$ & ASTM C 109 \\
\hline & & Tensile strength & Less than $1.0 \mathrm{MPa}$ & CRD-C 164 \\
\hline & & Tensile Bond strength & More than $1.5 \mathrm{MPa}$ & ASTM C 932 \\
\hline & & Drying shrinkage & Less than $0.1 \%$ & ASTM C 157 \\
\hline & & Elasticity & More than $5 \mathrm{GPa}$ & ASTM C 469 \\
\hline & & Thermal expansion & More than 16 millionths $/{ }^{\circ} \mathrm{C}$ & CRD-C 39 \\
\hline
\end{tabular}

\subsection{Evaluation Phase \\ 3.3.1 AHP-based Evaluation Process for Optimal Repair Material Selection}

The optimal repair selection model should be capable of considering the evaluation criteria objectively. Material selection is a typical multi-criteria decision-making problem owing to a large number of factors affecting decision making. AHP is a tool designed to solve MCDM problems, thus, AHP was applied in order to process repair materials selection that is typical multi-criteria decision making 
Table 4 Properties of repair materials alternatives chosen for evaluation.

\begin{tabular}{c|c|c}
\hline Repair alternatives & Classifications & Compositions \\
\hline \hline Repair A & PCM & $\begin{array}{c}\text { SBR modified-cement mortar adding } \mathrm{NO}_{2}- \\
\text { based anti-corrosion agent }\end{array}$ \\
\hline Repair B & PCM & Hydrotalcite, acrylate \\
\hline Repair C & PCM & $\begin{array}{c}\text { Nitrous lithium, silane, acrylic modified cement } \\
\text { mortar }\end{array}$ \\
\hline Repair D & FRM & Glass fiber, GGBS, OPC \\
\hline Repair E & PCM & PAE modified-cement mortar \\
\hline Repair F & RM & Epoxy mortar
\end{tabular}

Table 5 Pair-wise comparison matrix and standardized performance index (electrical resistivity).

\begin{tabular}{|c|c|c|c|c|c|c|}
\hline & \multicolumn{6}{|c|}{ Pairwise Comparison Matrix } \\
\hline & very low & low & moderate & negligible & Weights & Standardization \\
\hline \multirow{4}{*}{$\begin{array}{l}\text { very low } \\
\text { low } \\
\text { moderate } \\
\text { negligible }\end{array}$} & 1 & 3 & 5 & 7 & 0.565 & 1.000 \\
\hline & 0.333333 & 1 & 3 & 5 & 0.262 & 0.464 \\
\hline & 0.2 & 0.333333 & 1 & 3 & 0.118 & 0.208 \\
\hline & \begin{tabular}{|l|}
0.142857 \\
\end{tabular} & 0.2 & 0.333333 & 1 & 0.055 & 0.098 \\
\hline
\end{tabular}

Maximum Eigen Value $=4.11698$

C.I $=0.0389941$

Table 6 Pair-wise comparison matrix and standardized performance index (elasticity).

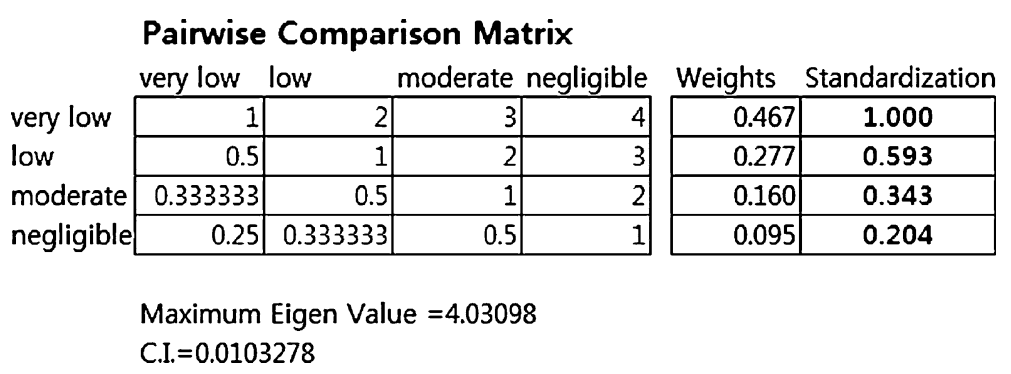

problem, of which calculation procedure has already been explained in the previous Sect. 2.

\subsubsection{Step 1: Choice and Performance Ttests of Repair Material Candidates for Optimal Selec- \\ tion The objective of this step is to choose the alterna-} tive materials for optimal repair material selection to be applied to chloride-deteriorated concrete member after filtering various repair materials according to the minimal performance criteria mentioned in previous section. And also the physical and chemical performance is measured using the measurement methods listed in Table 3.

Thus, based on the product specifications presented by manufacturer, six products listed in Table 4 were chosen as the optimal repair material candidates, which must satisfy the minimal requirements listed in Table 3. Table 7 shows the performance test results for performances of repair material alternatives that can be a possible optimal repair material according to measurement method listed in Table 3. This process is necessary to short-list the repair materials and to make a rational evaluation because it is impossible to evaluate a large number of repair materials at once.

\subsubsection{Step 2: Calculating Local Weights of each}

PEI The process of selecting the optimal repair material is composed of the 2 level-hierarchy structure as shown in Fig. 1 and Table 8 . The objective of this step is to decide a relative weight of performance evaluation items in each level, which refer to the difference of importance among criteria within the same level.

These relative weights within each level of hierarchy structure are regarded as local weights in this study and can 
be calculated as a method of pair-wise comparison using 9-point intensity defined in AHP theory mentioned in previous Sect. 2. In Tables 5 and 6 the respective local weights of the performance indicators (very low, low, moderate, negligible) of electrical resistivity and elasticity of several PEIs in Table 7 were listed. As explained previously these local weights of each PEI are evaluated by the relative evaluation method of comparative judgments that is pairwise comparison in AHP. The comparative judgments by pairwise comparison are very important to ensure the consistency of judgments of all things. In AHP the consistency ratio (CR) is used as a reference index to screen information of estimated pairwise comparison matrix. If $\mathrm{CR}<0.1$, then the comparisons are acceptable.
If, howerver, $\mathrm{CR} \geq 0.1$, then the value of the ratio is indicative of inconsistent judgments.

To determine the relative importance among the performance indicators (very low, low, moderate, negligible) of electrical resistivity, consistency ratio of the comparative judgments of Table 5 is calculated to be 0.01 . Likewise for elasticity the consistency ratio is 0.03 . Thus comparative judgments of electrical resistivity and elasticity are acceptable and the local weights of performances indicators is the value in Tables 5 and 6 .

Likewise the consistency ratios of pairwise comparison between each performance criteria comprising chemical performance criterion and physical performance criterion are 0.03 and 0.06 as shown in Tables 9 and 10 which are less

Table 7 Performance test results for each performance of repair materials alternatives according to the measurements of Table 3.

\begin{tabular}{|c|c|c|c|c|c|c|}
\hline $\begin{array}{c}\text { Repair Alt. } \\
\text { performance } \\
\text { evaluation items }\end{array}$ & Repair A & Repair B & Repair C & Repair D & Repair E & Repair F \\
\hline $\begin{array}{c}\text { Alkali resistance } \\
(\%)\end{array}$ & 0.30 & 0.02 & 0.10 & 0.50 & 1.20 & 0 \\
\hline $\begin{array}{c}\text { Chloride } \\
\text { permeability, C }\end{array}$ & 172 & 674 & 154 & 1024 & 947 & 13 \\
\hline $\begin{array}{c}\text { Electrical resistivity } \\
(\mathrm{k} \Omega \mathrm{cm})\end{array}$ & 324 & 214 & 421 & 64 & 108 & 1615 \\
\hline Bond Str. (MPa) & 1.8 & 2.1 & 1.2 & 1.6 & 2.3 & 3.7 \\
\hline $\begin{array}{c}\text { Compressive Str. } \\
(\mathrm{MPa})\end{array}$ & 27 & 43.2 & 28 & 63.7 & 36.1 & 83.5 \\
\hline $\begin{array}{c}\text { Drying shrinkage } \\
(\%)\end{array}$ & 0.024 & 0.048 & 0.031 & 0.030 & 0.002 & 0.063 \\
\hline Elasticity (GPa) & 28 & 25.5 & 18.6 & 36.6 & 29 & 14 \\
\hline Tensile Str. (MPa) & 4.8 & 3.5 & 1.5 & 2.2 & 2.8 & 38.2 \\
\hline $\begin{array}{c}\text { Thermal expansion } \\
\left.\text { (millionths } /{ }^{\circ} \mathrm{C}\right)\end{array}$ & 8.2 & 13 & 10.6 & 9.3 & 9.9 & 24 \\
\hline
\end{tabular}

Table 8 Global weight and local weight of each performance evaluation item.

\begin{tabular}{|c|c|c|c|}
\hline \multirow[t]{2}{*}{ 1st level } & \multirow[t]{2}{*}{ 2nd level } & \multicolumn{2}{|c|}{ Global weights } \\
\hline & & Unstandardized & Standardized $^{\mathrm{a}}$ \\
\hline \multirow{3}{*}{$\begin{array}{l}\text { Chemical requirement } \\
\text { (L:.417); R11 }\end{array}$} & Alkali resistance (L:.081); R21 & 0.0250 & 0.034 \\
\hline & $\begin{array}{l}\text { Chloride permeability } \\
\text { (L:.342); R22 }\end{array}$ & 0.1070 & 0.142 \\
\hline & $\begin{array}{l}\text { Electrical resistivity (L:.577); } \\
\text { R23 }\end{array}$ & 0.1800 & 0.240 \\
\hline \multirow{6}{*}{$\begin{array}{l}\text { Physical requirement } \\
\text { (L:.583); R12 }\end{array}$} & Bond strength (L:.219); R24 & 0.0960 & 0.128 \\
\hline & $\begin{array}{l}\text { Compressive strength } \\
\text { (L:.057); R25 }\end{array}$ & 0.0250 & 0.033 \\
\hline & Drying shrinkage (L:.396); R26 & 0.1730 & 0.231 \\
\hline & Elasticity (L:.089); R27 & 0.0390 & 0.052 \\
\hline & Tensile strength (L:.085); R28 & 0.0370 & 0.049 \\
\hline & Thermal expansion (L:.154); R29 & 0.0680 & 0.090 \\
\hline
\end{tabular}

\footnotetext{
${ }^{a}$ These values were normalized by dividing the global weight of each PEI into the sum of entire global weights.
} 
than the allowed value of 0.1 . Thus these pairwise comparisons are judged to be good.

\subsubsection{Step 3: Calculating the Global Weight} of each Required Performance The global weights of each performance criterion mean relative importance between performances. The global weight of each performance criterion in hierarchy structure of 2nd level can be calculated by multiplying itself by the local weight of upper level. With the method mentioned in step 2, the local weights of chemical and physical performance in the first level are calculated to be 0.417 and 0.583 respectively. And also, electrical resistivity, chloride permeability and alkali resistance in the second level of chemical performance are $0.081,0.342$ and 0.577 respectively. Thus, the global weights of the second level of chemical performance are obtained as $0.034,0.142$ and 0.240 from Eq. (9) as shown below. In the same way the global weights of each performance evaluation item in the second level of physical performances represented in hierarchy structure of Fig. 2 can be calculated as $0.128,0.033,0.231,0.052,0.049$, and 0.090 , respectively. repair alternative matches with the corresponding performance index which is set up using pair-wise comparison method as mentioned in Sect. 3.2. Seven candidates of repair materials were evaluated and indexed by performance indexes (listed in the right column of Table 11) corresponding to the measurement results. The evaluation values of chemical and physical performance of seven repair material alternatives are arrayed in left matrix in Eq. (10), where right matrix is the global weight matrix expressed by relative weights between performance evaluation items.

Eventually the evaluation on each candidate repair material is made by comparing relative weights of each performance evaluation item to all evaluation values of each candidate repair material like Eq. (10). The weighted evaluation value of each candidate repair material is given right 6 by 1 matrix of Eq. (10). Namely, the final weighted evaluation values of each repair materials alternative of Repair $\mathrm{A}$ to $\mathrm{F}$ are $0.197,0.131,0.135,0.153,0.199$, and 0.186 , respectively.

The evaluation result shows that selection of one of repair A and repair E could be the most optimal choice because the weighted evaluation values of these repair materials are the

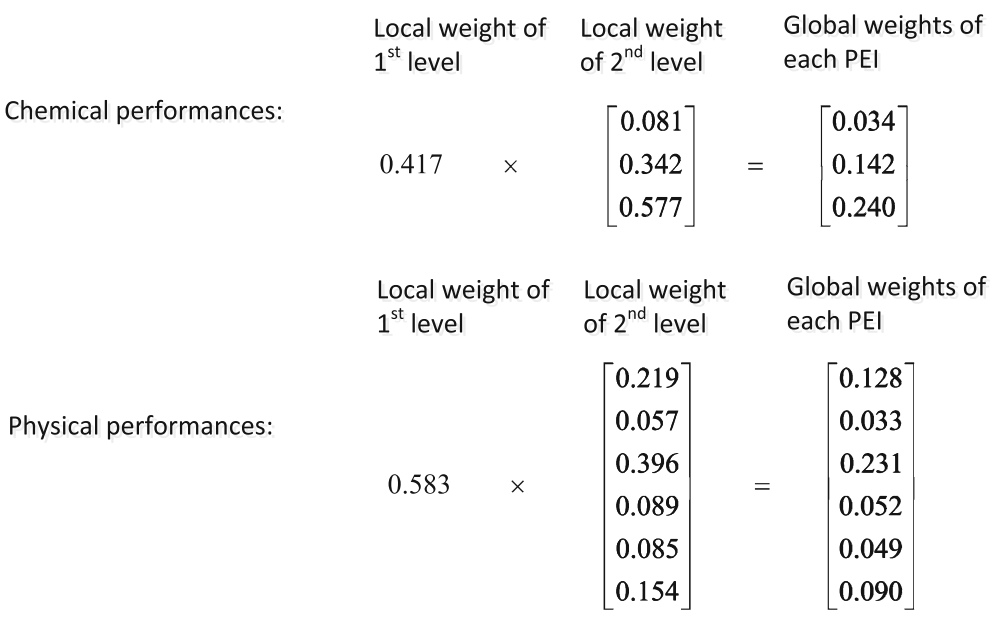

\subsection{Post-Evaluation and Review Phase \\ 3.4.1 Performance Evaluations of Possible Repair Materials and Ranking Candidate Materials}

In order to numerically evaluate the performance of repair alternative, measurement results of seven repair materials were indexed according to the performance indicator represented in Table 11. Each indicator of all performances of higher than those of other materials. Normally, designer or user can make a decision to select one of this two by comparing the cost or carrying out the additional evaluation like life cycle analysis and finally an optimal repair material satisfying the chemical and physical requirements is able to be selected by a rational and clear evaluation method. But Repair E is selected as the optimal repair materials applied to

Table 9 Pair-wise comparison matrix and standardized performance index (chemical performance).

\begin{tabular}{c|c|c|c|c}
\hline Chemical performance & Chloride permeability & Alkali-resistance & Electrical resistivity & Relative weights \\
\hline \hline Chloride permeability & 1.000 & 5.000 & 0.500 & 0.342 \\
\hline Alkali-resistance & & 1.000 & 0.167 & 0.081 \\
\hline Electrical resistivity & & & 1.000 & 0.577 \\
\hline
\end{tabular}

Italic numbers are the relative significanes expressed from 1 to 9 for making pair-wise comparisons with the vertical to the horizontal Inconsistency: 0.03 . 
Table 10 Pair-wise comparison matrix and standardized performance index (physical performance).

\begin{tabular}{|c|c|c|c|c|c|c|c|}
\hline $\begin{array}{c}\text { Physical } \\
\text { performance }\end{array}$ & $\begin{array}{c}\text { Compressive } \\
\text { strength }\end{array}$ & Tensile strength & $\begin{array}{l}\text { Adhesive } \\
\text { strength }\end{array}$ & $\begin{array}{c}\text { Drying } \\
\text { shrinkage }\end{array}$ & Elasticity & $\begin{array}{c}\text { Thermal } \\
\text { expansion }\end{array}$ & Relative weights \\
\hline $\begin{array}{c}\text { Compressive } \\
\text { strength }\end{array}$ & 1.000 & 0.500 & 0.250 & 0.167 & 0.500 & 0.629 & 0.057 \\
\hline Tensile strength & & 1.000 & 0.200 & 0.200 & 1.000 & 0.820 & 0.085 \\
\hline $\begin{array}{r}\text { Adhesive } \\
\text { strength }\end{array}$ & & & 1.000 & 0.333 & 3.000 & 0.787 & 0.219 \\
\hline Drying shrinkage & & & & 1.000 & 5.000 & 1.610 & 0.396 \\
\hline Elasticity & & & & & 1.000 & 0.826 & 0.089 \\
\hline $\begin{array}{l}\text { Thermal } \\
\text { expansion }\end{array}$ & & & & & & 1.000 & 0.154 \\
\hline
\end{tabular}

Italic numbers are the relative significanes expressed from 1 to 9 for making pair-wise comparisons with the vertical to the horizontal Inconsistency: 0.06 .

chloride-deteriorated concrete because the scope of this study is to investigate the rational and evident process for selecting an optimal repair material under the given deterioration environment like process of structure design or product design which are subdivide into preliminary design, embodiment design, and finally detail (parametric design) (Keoleian et al. 2005; Ashby and Johnson 2002; Fitch and Cooper 2004; Stuart and Sommerville 1998; Edward 2007).
Table 8, and R21 is the performance index of alkali resistance in Table 11 corresponding with its measurement value for each candidate repair material. And also, R22 = chloride permeability, R23 = Electrical resistivity, R24 = bond strength, $\mathrm{R} 25=$ compressive strength, $\mathrm{R} 26=$ drying shrinkage, R27 = elasticity, R28 = tensile strength, and $\mathrm{R} 29=$ thermal expansion, respectively.
Evaluation value of

Quantitative Performance

"QC31" "QC32" "QC33" "QP31" "QP32" "QP33" "QP34" "QP35" "QP36"

"Repair A" $\left[\begin{array}{lllllllll}0.160 & 0.146 & 0.228 & 0.071 & 0.062 & 0.325 & 0.193 & 0.202 & 0.265\end{array}\right.$

$\begin{array}{lllllllllll}\text { "Repair B" } & 0.160 & 0.146 & 0.106 & 0.165 & 0.139 & 0.062 & 0.193 & 0.202 & 0.055\end{array}$

$\begin{array}{lllllllllll}\text { "Repair C" } & 0.160 & 0.146 & 0.228 & 0.071 & 0.062 & 0.130 & 0.114 & 0.072 & 0.123\end{array}$

\begin{tabular}{l|llllllllll} 
"Repair D" & 0.160 & 0.092 & 0.106 & 0.071 & 0.299 & 0.130 & 0.193 & 0.121 & 0.265
\end{tabular}

\begin{tabular}{l|lllllllll} 
"Repair E" & 0.092 & 0.146 & 0.106 & 0.165 & 0.139 & 0.325 & 0.193 & 0.202 & 0.265
\end{tabular}

\begin{tabular}{l|llllllllll} 
& "Repair F" & 0.269 & 0.322 & 0.228 & 0.459 & 0.299 & 0.029 & 0.114 & 0.202 & 0.026
\end{tabular}
Relative weights of Final weighted evaluation performance criteria results of each candidate

$\left[\begin{array}{l}0.025 \\ 0.107 \\ 0.180 \\ 0.096 \\ 0.025 \\ 0.173 \\ 0.039 \\ 0.037 \\ 0.068\end{array}\right]=\left[\begin{array}{l}0.197 \\ 0.131 \\ 0.135 \\ 0.153 \\ 0.199 \\ 0.186\end{array}\right]$

\subsubsection{Simple Performance Evaluation Equation} for Optimal Repair Material Selection

Arranging this study result for the purpose of the practical usage of this evaluation process, the following equations can be presented for evaluating various repair alternatives to be applicable to repair the chloride-deteriorated concrete members.

$$
\begin{aligned}
& {[(0.034 \times R 21)+(0.1042 \times R 22)+(0.240 \times R 23)]} \\
& +\left[\begin{array}{r}
(0.128 \times R 24)+(0.033 \times R 25)+(0.231 \times R 26) \\
+(0.052 \times R 27)+(0.049 \times R 28)+(0.090 \times R 29)
\end{array}\right]
\end{aligned}
$$

In which, the coefficients of each variable indicate the global weights of performance evaluation indices listed in

\section{Conclusions}

In contrast to other design process like concrete mix design, structural design or product design, the present process for selecting repair materials has been very illogical and cannot be regarded as an engineering approach. Nevertheless, the rational process for selecting optimal repair materials will be needed in order to save the cost and to assure the quality of repair work.

Among MCDM solvers, AHP is a very effective and easy way to assess the relative importance of each performance criterion of MCDM and evaluate comprehensively various candidate repair materials. The methodology based on AHP was suggested in this paper for the selection of a suitable material from among a large number of available repair 
Table 11 Indicators of each required performance and those corresponding performance indices.

\begin{tabular}{|c|c|c|c|c|}
\hline Required performance & & $\begin{array}{l}\text { Meaning of performance } \\
\text { indicator }\end{array}$ & Indicator & Performance index \\
\hline \multirow[t]{12}{*}{ Chemical performance } & \multirow{4}{*}{$\begin{array}{l}\text { Alkali resistance; } \\
\text { QC31 }\end{array}$} & Less than $0 \%$ & Very low & 1.000 \\
\hline & & 0 to $1 \%$ & Low & 0.593 \\
\hline & & 1 to $3 \%$ & Moderate & 0.343 \\
\hline & & More than $3 \%$ & Negligible & 0.204 \\
\hline & \multirow{4}{*}{$\begin{array}{l}\text { Chloride Permeability; } \\
\text { QC32 }\end{array}$} & Less than $100 \mathrm{C}$ & Very low & 1.000 \\
\hline & & 100 to 1000 & Low & 0.455 \\
\hline & & 1000 to 2000 & Moderate & 0.286 \\
\hline & & 2000 to 4000 & Negligible & 0.105 \\
\hline & \multirow{4}{*}{$\begin{array}{c}\text { Electrical resistivity; } \\
\text { QC33 }\end{array}$} & More than $254 \mathrm{k} \Omega \mathrm{cm}$ & Very high & 1.000 \\
\hline & & 37 to $254 \mathrm{k} \Omega \mathrm{cm}$ & High & 0.464 \\
\hline & & 21 to $37 \mathrm{k} \Omega \mathrm{cm}$ & Moderate & 0.208 \\
\hline & & 12 to $21 \mathrm{k} \Omega \mathrm{cm}$ & Low & 0.098 \\
\hline \multirow[t]{24}{*}{ Physical performance } & \multirow[t]{4}{*}{ Bond strength; QP31 } & More than $3.0 \mathrm{MPa}$ & Very high & 1.000 \\
\hline & & 3.0 to $2.5 \mathrm{MPa}$ & High & 0.601 \\
\hline & & 2.5 to $2.0 \mathrm{MPa}$ & Moderate & 0.359 \\
\hline & & 2.0 to $1.5 \mathrm{MPa}$ & Low & 0.154 \\
\hline & \multirow{4}{*}{$\begin{array}{c}\text { Compressive strength; } \\
\text { QP32 }\end{array}$} & More than $50 \mathrm{MPa}$ & Very high & 1.000 \\
\hline & & 30 to $50 \mathrm{MPa}$ & High & 0.464 \\
\hline & & 27 to $30 \mathrm{MPa}$ & Moderate & 0.208 \\
\hline & & Less than $27 \mathrm{MPa}$ & Low & 0.098 \\
\hline & \multirow[t]{4}{*}{ Drying strength; QP33 } & Less than $0.03 \%$ & Very low & 1.000 \\
\hline & & 0.03 to $0.04 \%$ & Low & 0.400 \\
\hline & & 0.04 to $0.05 \%$ & Moderate & 0.190 \\
\hline & & 0.05 to $0.1 \%$ & Negligible & 0.090 \\
\hline & \multirow{4}{*}{$\begin{array}{l}\text { Elasticity; } \\
\text { QP34 }\end{array}$} & More than $20 \mathrm{GPa}$ & Very high & 1.000 \\
\hline & & 13 to $20 \mathrm{GPa}$ & High & 0.593 \\
\hline & & 8 to $13 \mathrm{GPa}$ & Moderate & 0.343 \\
\hline & & 5 to $8 \mathrm{GPa}$ & Low & 0.204 \\
\hline & \multirow{4}{*}{$\begin{array}{c}\text { Tensile strength; } \\
\text { QP35 }\end{array}$} & More than $2.5 \mathrm{MPa}$ & Very high & 1.000 \\
\hline & & 2.5 to $2.0 \mathrm{MPa}$ & High & 0.601 \\
\hline & & 2.0 to $1.5 \mathrm{MPa}$ & Moderate & 0.359 \\
\hline & & 1.5 to $1.0 \mathrm{MPa}$ & Low & 0.154 \\
\hline & \multirow{4}{*}{$\begin{array}{c}\text { Thermal expansion; } \\
\text { QP36 }\end{array}$} & Less than 10 millionths $/{ }^{\circ} \mathrm{C}$ & Very low & 1.000 \\
\hline & & 10 to 12 millionths $/{ }^{\circ} \mathrm{C}$ & Low & 0.464 \\
\hline & & 12 to 14 millionths $/{ }^{\circ} \mathrm{C}$ & Moderate & 0.208 \\
\hline & & 14 to 16 millionths $/{ }^{\circ} \mathrm{C}$ & Negligible & 0.098 \\
\hline
\end{tabular}


material alternatives for a chloride-deteriorated concrete member. This study is expected to be able to present the rational decision-making tools using AHP to repair materials selection with multi-criteria attributes. As a result of study, the equation for the evaluation was obtained in the simple form, which will be applicable to the practical work. This study result will be very effective approach, for solving the problem of repair materials selection cooperating LCC analysis. The minimal performance criteria prepared in this study may be further updated in order to achieve a successful repair work for chloride-deteriorated concrete structure.

\section{Acknowledgements}

This work was supported by the National Research Foundation of Korea Grant funded by the Korean Government (Ministry of Education, Science and Technology) [NRF2010-359-D00026] and [KRF-2009-1-D00040].

\section{Open Access}

This article is distributed under the terms of the Creative Commons Attribution License which permits any use, distribution, and reproduction in any medium, provided the original author(s) and the source are credited.

\section{References}

ACI546.3R-06. (2006). Guide to the selection of materials for the repair of concrete.

ACI546R-04. (2004). Concrete Repair Guide, 2004.

ACI548.1R. (2004). Guide for the use of polymers in concrete. ACI201.2R. (2004). Guide to Durable Concrete.

Al-Zahrani, M., et al. (2003). Mechanical properties and durability characteristics of polymer-and cement-based repair materials. Cement and Concrete Composites, 25(4) 527537.

Ashby, M. (2000). Multi-objective optimization in material design and selection. Acta Materialia, 48(1), 359-370.

Ashby, M. F. (2005). Materials selection in mechanical design, Oxford: Butterworth-Heinemann.

Ashby, M. F., \& Johnson, K. (2002). Materials and design: The art and science of material selection. In Product design (2nd Ed.). Oxford: Butterworth-Heinemann.

Bamkin, R., \& Piearcey, B. (1990). Knowledge-based material selection in design. Materials and Design, 11(1), 25-29.

Beushausen, H. D., \& Alexander, M. (2007). Performance of concrete patch repair systems. Advances in Construction Materials 2007, 255-262.

Chawalwala, A. F. (1999). Material characteristics of polymer concrete. Technical Report, University of Delaware Center of Composite Materials.

Chen, R.W., et al. (1994). A systematic methodology of material selection with environmental considerations. Electronics and the Environment, IEEE International Symposium, Pittxburgh, PA, May 1994, pp. 252-257.

Cusson, D., \& Mailvaganam, N. (1996). Durability of repair materials, Concrete International-Design and Construction, 18(3), 34-38.

Danish Standards Association (2004). Repair of concrete structures to EN 1504. Oxford: Butterworth-Heinemann.

Do, J. (2009). Performance configuration and optimal selection of patching repair materials for concrete structure using AHP, 1st Asia Pacific Young Researchers and Graduates Symposium, Kunsan, pp. 43-51.

Edward, C. (2007). Concrete design, service life and repair strategy: A new European standard.

Emmons, P. P. H. (1995). Performance criteria for concrete repair materials. Phase 1 , DTIC Document.

Emmons, P. P. et al. (2000). Selecting durable repair materials, performance criteria. Concrete International, 22(3), 38-46.

EN1504-series. (2002). Products and systems for protection and repair of concrete structure. Definitions, requirements, quality concrol and evaluation of conformity.

Fitch, P. P. E., \& Cooper, J. S. (2004). Life cycle energy analysis as a method for material selection. Journal of Mechanical Design, 126(4), 798-804.

Holloway, L. (1998). Materials selection for optimal environmental impact in mechanical design. Materials and Design, 19(4), 133-143.

ICRINo. 320.2R. (2009). Guide for selecting and specifying materials for repair of concrete surfaces.

ICRINo.320.1R. (1996). Guide for selecting application methods for the repair of concrete surfaces.

ICRINo.330.1. (2006). Guide for the selection of strengthening systems for concrete structures.

Ishii, K. (1996). Material selection issues in design for recyclability. The Second International EcoBalnce Conference, Tsukuba, Japan.

Jalham, I. S. (2006). Decision-making integrated information technology (IIT) approach for material selection. International Journal of Computer Applications in Technology, 25(1), 65-71.

Jee, D. H., \& Kang, K. J. (2000). A method for optimal material selection aided with decision making theory. Materials and Design, 21(3), 199-206.

Keoleian, G. A. et al. (2005). Life cycle modeling of concrete bridge design: Comparison of engineered cementitious composite link slabs and conventional steel expansion joints. Journal of Infrastructure Systems, 11(1), 51-60.

Kosednar, J., \& Mailvaganam N. P. P. (2005). Selection and use of polymer-based materials. In the repair of concrete structures. Journal of performance of constructed facilities, 10(3) 229-233.

Liao, T. W. (1996). A fuzzy multicriteria decision-making method for material selection. Journal of Manufacturing Systems, 15(1), 1-12.

Mailvaganam, N. P. P. (2001). Concrete repair and rehabilitation, issues and trends. Indian Concrete Journal, 75(12), 759-764.

McDonald, J., et al. (2000). Development of performance criteria for dimensionally compatible cement-based repair materials. ACI Special Publications, 193, 441-458. 
Nabhan, F. (2007). Selection of repair materials using expert advice. Indian Concrete Journal, 81(6), 51-54.

Rao, R. V. (2006). A material selection model using graph theory and matrix approach. Materials Science and Engineering, 431(12), 248-255.

Rao, R. V. (1954). A decision making methodology for material selection using an improved compromise ranking method. Materials and Design, 29(10), 1949-1954.

Rao, R. \& Davim, J. (2008). A decision-making framework model for material selection using a combined multiple attribute decision-making method. The International Journal of Advanced Manufacturing Technology, 35(7), 751-760.

Raupach, M. (2006). Concrete repair according to the new European standard EN 1504. Concrete Repair, Rehabilitation and Retrofitting. London: Taylor \& Francis Group.

Rizzo, E. M., \& Sobelman M. B. (1989). Selection criteria for concrete repair materials. Concrete International, 11(9), 46-49.

Saaty, T. L. (1980). The analytical hierarchy process. McGrawHill, New York.

Saaty, T. L. (1990). The Analytic Hierarchy Process: Planning, Priority Setting, Resource Allocation (Decision-Making Series). New York: Mcgraw-Hill.

Saaty, T. L. (1990). How to make a decision, The analytic hierarchy process. European Journal of Operational Research, 48(1), 9-26.

Saaty, T. L. (1994). Fundamentals of decision making. Pittsburgh: RWS Publications.

Saaty, T. L. (1994). How to make a decision: The analytic hierarchy process. European Journal of Operational Research, 48(1), 9-26.

Saaty, T. L. (2008). Decision making with the analytic hierarchy process. International Journal of Services Sciences, 1(1), 83-98.

Saaty, T. L., \& Vargas L. G. (1987). Uncertainty and rank order in the analytic hierarchy process. European Journal of Operational Research, 32(1), 107-117.

Sapuan, S. (2001). A knowledge-based system for materials selection in mechanical engineering design. Materials and Design, 22(8), 687-695.

Shanian, A., \& Savadogo, O. (2006). A material selection model based on the concept of multiple attribute decision making. Materials and Design, 27(4), 329-337.

Singh, V. (2005). Selection of polymers for repair and rehabilitation of RC structures. Indian Concrete Journal, 10 35-38.
Sirisalee, P. P., et al. (2004). Multi-criteria material selection in engineering design. Advanced Engineering Materials, 6(12), 84-92.

Smith, R. L., Bush R. J., \& Schmoldt D. L. (1997). The selection of bridge materials utilizing the analytical hierarchy process, Notes.

Smith, R. L., Bush R. J., \& Schmoldt D. L. (1995). A hierarchical model and analysis of factors affecting the adoption of timber as a bridge material. Wood and Fiber Science, 27(3), 225-238.

Smith, W. F., \& Hashemi J. (2006). Foundations of materials science and engineering (4th ed.). New York: Mcgraw Hill.

Steeves, C. A., \& Fleck N. A. (2004). Material selection in sandwich beam construction. Scripta Materialia, 50(10), 1335-1339.

Stuart, J. A., \& Sommerville, R. M. (1998). Materials selection for life cycle design. IEEE.

Vaidya, O. S., \& Kumar, S. (2006). Analytic hierarchy process, An overview of applications. European journal of operational research, 169(1), 1-29.

Vargas, L. G. (1990). An overview of the analytic hierarchy process and its applications. European Journal of Operational Research, 18(1), 2-8.

Vaysburd, A., et al. (2000). Performance criteria for selection of repair materials. ACI Special Publications, 192, pp. 931-948.

Vaysburd, A. et al. (2000). Selecting durable repair materials, performance criteria-field studies. Concrete International, 22(12), 39-45.

Vokurka, R. J., Choobineh, J., \& Vadi, L. (1996). A prototype expert system for the evaluation and selection of potential suppliers. International Journal of Operations \& Production Management, 16(12), 106-127.

Yurdakul, M. (2004). AHP as a strategic decision-making tool to justify machine tool selection. Journal of Materials Processing Technology, 146(3), 365-376.

Zahedi, F. (1986). The analytic hierarchy process: A survey of the method and its applications. Interfaces, 16, 96-108.

Zahedi, F. (1986). The analytic hierarchy process: A survey of the method and its applications. Interfaces, 16(4), 96-108.

Zhou, C. C., Yin, G. F., \& Hu, X. B. (2009). Multi-objective optimization of material selection for sustainable products, artificial neural networks and genetic algorithm approach. Materials and Design, 30(4), 1209-1215. 